\title{
O falar de Marvão: contributos para o seu estudo
}

\author{
Teresa Susana BENGALA SIMÃo \\ CIDEHUS - Universidade de Évora \\ tssimao@portugalmail.pt
}

\section{RESUMO}

Este artigo é uma síntese da investigação em curso sobre o falar raiano de Marvão, um concelho do Nordeste Alentejano que faz fronteira com Valência de Alcântara, na Extremadura Espanhola.

Depois de uma breve caracterização do território em estudo, é feito o enquadramento do Falar de Marvão no panorama dialectal português e a apresentação das suas principais características, sobos pontos de vista fonético-fonológico, morfossintático e lexical. Ainda que este falar apresente muitas das características identificadas pelos linguistas do século XX sobre esta região dialetal, demarca-se por algumas particularidades que o distinguem dos falares dos concelhos limítrofes..

Palavras chave: dialectologia, falares de raia, variação linguística, Marvão, património imaterial.

[Recibido, marzo 2012; aprobado, mayo 2012]

\section{The dialect of Marvão: contributions for its study}

\begin{abstract}
This article is a synthesis of the ongoing research about the border dialect of Marvão, a district in the north-west of Alentejo which borders Valência de Alcântara in Extremadura, Spain. Firstly it presents a brief characterization of the territory in study; secondly it shows how the dialect of Marvão fits in the overwiew of Portuguese dialects and it presents its main features under the phonetic-phonological, morphological, syntactic and lexical viewpoints. Although this dialect presents many of the characteristics identified by the linguistics of the $20^{\text {th }}$ century on this dialectical region, it is distinguished due to some particularities which make it different from other dialects of the border districts.
\end{abstract}

Keywords: dialectology, border dialects, linguistic variation, Marvão, intangible heritage. 


\section{Introdução}

Este artigo visa apresentar uma síntese do estudo que está em curso sobre o Falar de Marvão (um concelho de raia do Norte Alentejo), iniciado em 2003 e presentemente em desenvolvimento.

O referido trabalho teve início aquando da pós-gradução em Cultura, Língua e Comunicação, na Universidade da Beira Interior, continuou a ser desenvolvido durante a frequência do mestrado em Ciências da Linguagem e da Comunicação, na Universidade de Évora, tendo continuidade no âmbito do doutoramento em Linguística, na mesma academia.

Para além do conhecimento empírico da autora, já que é natural do concelho em estudo, o trabalho tem por base a aplicação de inquéritos linguísticos preparados para o efeito e adequados às características do concelho e seus falantes. Acresce a esta situação, mais formal, a observação direta, já que a autora trabalha no concelho e permanentemente contacta com diferentes tipos de falantes, efetuando, assim, uma vasta recolha informal.

Se, numa primeira fase, o estudo se centrou nos falantes acima dos setenta anos e preferencialmente analfabetos, o seu desenvolvimento pretende conhecer a realidade linguística de todos os falantes, de modo a compreender a sua evolução de acordo com as diferentes camadas etárias e o grau de instrução.

Nesta fase do estudo, pretende-se apresentar aqui uma panorâmica geral do Falar de Marvão, dando conta dos seus principais aspetos fonético-fonológicos, morfossintáticos e lexicais.

\section{Breve caracterização do concelho de Marvão}

Geograficamente, o concelho de Marvão fica localizado no Nordeste Alentejano, no distrito de Portalegre, e tem como limites: a norte/este, o rio Sever (que delimita a fronteira entre Portugal e Espanha), a sul, o concelho de Portalegre e, a oeste, o concelho de Castelo de Vide. 


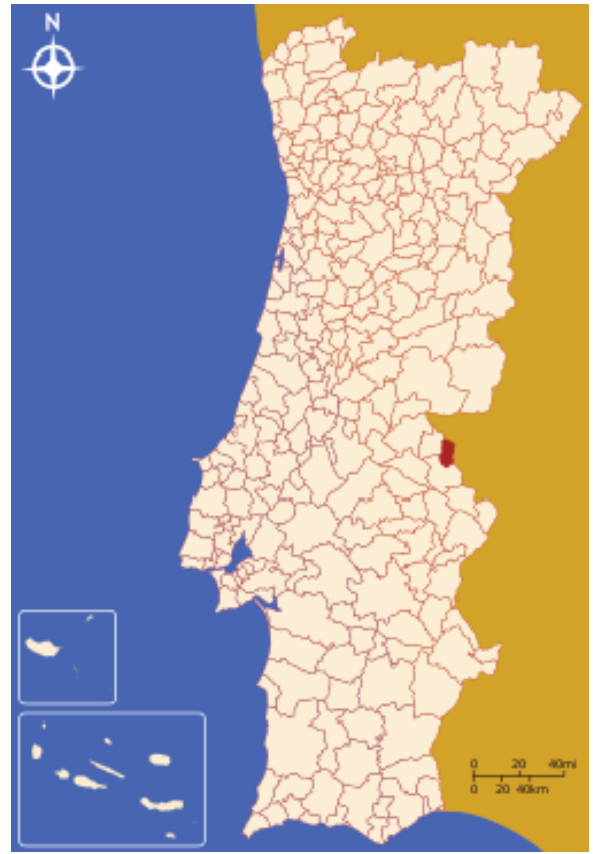

Ilustração 1: Mapa que evidencia a localização de Marvão no contexto português

Com uma área de $154,9 \mathrm{~km}^{2}$, distribuída por quatro freguesias, nomeadamente, Beirã e Santo António das Areias, a norte, Santa Maria de Marvão e São Salvador de Aramenha, a sul, o concelho apresenta uma densidade populacional muito baixa - 22,67 habitantes $/ \mathrm{km}^{2}$. Segundo dados dos censos de 2011 apresentados pelo Instituto Nacional de Estatística (I.N.E.), Marvão tem cerca de 3512 habitantes, verificando-se uma diminuição da população de $11,81 \%$ relativamente aos censos de 2001.

$\mathrm{Na}$ década de 50 do século passado, verificou-se um pico demográfico, essencialmente na zona norte do concelho, devido a um grande desenvolvimento da agricultura e da indústria. Desde então, a população tem vindo sempre a diminuir, havendo uma redução de cerca de 500 habitantes na última década, motivada pela falta de emprego no concelho, que conduz à desertificação, e pelo acentuado envelhecimento dos residentes.

Nos anos 70 e 80, assistiu-se a um declínio, quer na agricultura, quer na indústria, enquadrando-se a população atual essencialmente no setor terciário.

Quanto ao grau de escolarização da população, a taxa de analfabetismo continua elevada, cerca de $25,77 \%$, o que vem ao encontro do acentuado índice de envelhecimento da população, já que as gerações mais velhas são menos instruídas. 


\section{Enquadramento do falar de Marvão no contexto dialetal português}

Nos finais do século XIX, quando Leite de Vasconcelos traçou o mapa dialetal de Portugal, o concelho de Marvão enquadrava-se no subdialeto de Fundão, Castelo Branco e Portalegre (Vasconcelos 1897: 15, 16). No início do século XX, em 1901, esta região passou a integrar a área do dialeto meridional, mais concretamente do subdialeto alentejano (Vasconcelos 1987: 28-125), e, em 1929, do subdialeto do Alto Alentejo (Vasconcelos 1929: 795).

Em 1959, Manuel de Paiva Boléo e Maria Helena Santos Silva definiram um novo mapa dialetológico, ficando o concelho em estudo enquadrado na área do falar de Castelo Branco e Portalegre, mais especificamente, no subfalar de Portalegre (Boléo 1962: 100).

Posteriormente, em 1971, Lindley Cintra apresentou uma nova proposta de classificação dos dialetos portugueses, passando o concelho de Marvão a estar integrado na área dos dialetos portugueses centro-meridionais, no grupo de dialetos do centro-interior e sul, mais concretamente na região da Beira Baixa e Alto Alentejo (Cintra 1995: 141 - 163; Cunha 2006: 11).

\section{Principais aspetos fonético-fonológicos do falar de Marvão}

O falar de Marvão partilha algumas das características fonético-fonológicas identificadas pelos diversos linguistas nesta região do Alentejo, nos finais do século XIX e ao longo do século XX, e apresenta especificidades que o distinguem de outros falares norte alentejanos.

\subsection{Vocalismo tónico}

No que concerne às vogais orais, é de salientar sobretudo a palatalização de [a] ${ }^{1} \mathrm{e}$ [e.]para $[\varepsilon]$ e $[\mathrm{e}]$, como exemplificam:

[bugé Ku].(bugalho), [brikḱrr](brincar), [beljér.](balear);

[sigếne] (cigana), [eRibếne] (arribana).

De notar que, no segundo exemplo, é ainda evidente um timbre nasalado, provocado pela consoante nasal que se segue, o que constitui uma das características do subdialeto alentejano apontadas por Leite de Vasconcelos.

Nas aldeias de Escusa e Porto da Espada (nesta de forma já mais esbatida), verifica-se uma palatalização do $[\mathrm{u}]$, passando a $[\ddot{\mathrm{u}}]^{2}$ :

${ }^{1}$ Cf. VASCONCELOS, 1901: 78. Segundo este autor, esta alteração, além de se verificar no Alto Alentejo, é comum à Beira Baixa e à Beira Alta. CINTRA, 1995: 156. Mais tarde, Cintra constata que a palatalização do $a$ tónico nesta região verifica-se quando este contacta com consoante ou semivogal palatal ou quando, na sílaba anterior, existe ou existiu uma das vogais ou semivogais átonas $i$ ou $u$. BAPTISTA, 1967: 15. 


\section{[túdì]](tudo), [ürne] (urna), [ẽtrúdì] (Entrudo).}

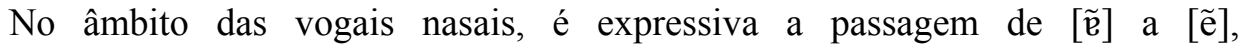
especialmente quando a vogal nasal é antecedida por vogal ou semivogal palatal:

[îftudếti] (estudante), [irmế] (irmã), [kõfjếse]

Muito frequente, na aldeia de Escusa e com alguns vestígios em Porto da Espada, é a palatalização de [ũ] $]^{3}$ :

[fứdi] (fundo), [mû́di] (mundo), [klerimû́du] (Clarimundo).

\subsection{Vocalismo átono}

Nas vogais orais, são de destacar as diversas mutações de timbre da vogal [e], provocadas, quer por assimilação, quer por dissimilação, sendo a mais significativa o fechamento para $[\mathrm{i}]^{4}$ :

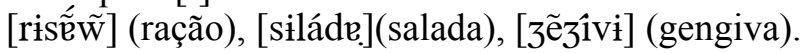

Por norma, verifica-se uma centralização e fechamento da vogal $[\varepsilon]$ para $[\mathfrak{e}]$, sobretudo quando a vogal antecede uma consoante alveolar velarizada:

[imóveł] (imóvel), [ipikáveł] (impecável), [túneł] (túnel).

A passagem de $[\mathrm{i}] \mathrm{a}[\mathrm{e}]^{5}$ e $[\mathrm{u}]^{6}$ representa outra marca bem vincada do Falar de Marvão. Esta resulta de assimilações ou da presença de uma vibrante contígua:

[enedóte] (anedota), [ẽdráde] (Andrade), [3ezúf] (Jesus);

[pupi)nu] (pepino), [bubér] (beber), [furmếtu](fermento).

De salientar ainda a centralização de $[\mathrm{u}]$ para $[\mathrm{i}]^{7}$, especialmente em posição postónica, a qual representa uma marca distintiva dos falantes da zona norte do concelho e é partilhada pelos mais idosos, pelos adultos e pelos mais jovens:

\footnotetext{
${ }^{2}$ Cf. VASCONCELOS, 1901: 83. O linguista regista a existência deste [ü] numa vasta região, que se estende desde o meio do Fundão e da Sertã até Portalegre e que compreende alguns territórios da Estremadura, aparecendo também no Algarve. BAPTISTA, 1967: 21, 22. A autora considera este timbre quase sistematicamente palatal como uma das características mais acentuadas do falar da Escusa.

${ }^{3}$ Cf. BAPTISTA, 1967: 27.

${ }^{4}$ Cf. VASCONCELOS, 1987: 85. Na perspetiva deste autor, esta transformação deve-se por vezes ao fenómeno de dissimilação. BAPTISTA, 1967: 31, 38.

${ }^{5}$ Cf. VASCONCELOS, 1896: 33. Esta mudança é justificada com a proximidade de um $r$, que faz com que o $e$ átono vizinho passe a $a$ : "rabanho, taria, sará". Além desta influência, também se nota a influência do $n$ e do $s$ sobre o $\dot{x}$ átono medial. BAPTISTA, 1967: 33.

${ }^{6}$ Cf. VASCONCELOS, 1987: 103. Ainda que considere a influência das labiais um fenómeno esporádico, na Estremadura, por influência das labiais, há frequentemente uma transformação do $e$ átono em $u$. BAPTISTA, 1967: 34.

${ }^{7}$ Cf. VASCONCELOS, 1987: 88. Segundo o autor, esta transformação deve-se a um fenómeno de dissimilação, embora também possa advir de outras alterações esporádicas. BAPTISTA, 1967: 39, 40.
} 
[mifîle] (mochila), [êtîgì] (antigo), [kemî́nị] (caminho).

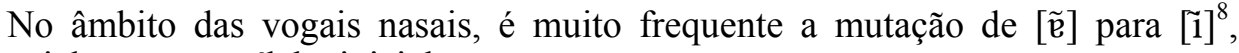
especialmente em sílaba inicial:

[ỉbulếš].(ambulância), [13ź́łke](Angélica), [kitéru] (canteiro).

Quanto à vogal [ẽ] apresenta diversas alterações de timbre, sendo as mais comuns a centralização para $[\tilde{\mathfrak{e}}]^{9}$, bem como o seu fechamento para [1] $]^{10}$, em posição pretónica:

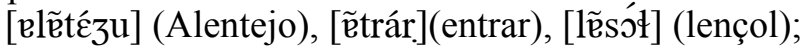

[emĩduére](amendoeira), [ỉbúdị] (embude), [ỉbóre] (embora).

Tal como nas vogais tónicas, verifica-se uma palatalização do $[\tilde{u}]$ para $\left[\mathrm{u}_{-}\right]^{11}$, todavia, esta apenas caracteriza as gentes da aldeia de Escusa: [ứtu] (unto).

\subsection{Ditongos}

Integrando-se o Falar de Marvão nos falares do Alentejo, verifica-se uma forte tendência para a monotongação.

No que diz respeito aos ditongos decrescentes orais, destacamos aqui a monotongação no [aj $]^{12}$ e no [uj] ${ }^{13}$ (somente em sílaba pretónica):

[Sáli] (xaile), [kája] (caixa), [ebáfu] (abaixo);

[uvár] (uivar), [kudár](cuidar).

No âmbito dos ditongos crescentes, é de salientar a redução do [ja] em posição postónica, bem como uma transposição da semivogal para outra posição do vocábulo, motivada por uma metátese:

[Érne] (hérnia), [siếse] (ciência), [ewzếse] (ausência);

[kuftójde](Custódia), [lerájpe] (larápia), [kuméjde] (comédia).

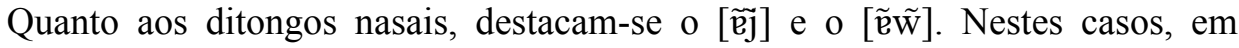
posição tónica, além de uma redução (sendo esta mais vincada na aldeia da Escusa $^{14}$ ), verifica-se uma desnasalização ${ }^{15}$ :

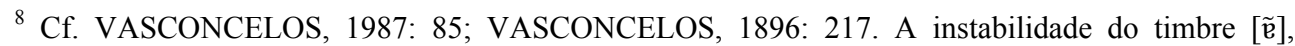
alterando-se para [ẽ] ou [i]], surge em diversos dialetos portugueses.; BAPTISTA, 1967: 40.

${ }^{9}$ Cf. BAPTISTA, 1967: 41, 43, 44; VASCONCELOS, 1987: 87.

${ }^{10}$ Cf. VASCONCELOS, 1987: 86, 87; VASCONCELOS, 1896: 217; BAPTISTA, 1967: 41, 44.

${ }^{11}$ Cf. BAPTISTA, 1967: 42.

${ }^{12}$ Cf. VASCONCELOS, 1896: 216. A propósito das características da linguagem de Avis, o autor registou que antes de [S] não se desenvolve a semivogal [j], por exemplo: "baxo, quexo". VASCONCELOS, 1987: 92. O linguista considera esta redução característica dos dialetos do Sul, verificando-se esta em próclise. Todavia, como podemos constatar, no falar de Marvão este é um fenómeno mais abrangente. BAPTISTA, 1967: 47, 48.

13 Cf. VASCONCELOS, 1987: 94; BAPTISTA, 1967: 55. Na Escusa, foi registada uma monotongação em todos os contextos e para [u]. 


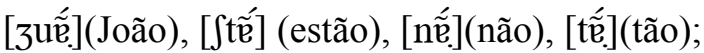

[kuráze] (coragem), [garáze] (garagem), [purtáze] (Portagem).

De notar que o ditongo $[\tilde{\mathfrak{e}} \tilde{\mathrm{w}}]$ por vezes apresenta uma alteração para $[\tilde{\mathrm{e}} \tilde{\mathrm{w}}]^{16}$, o que constitui mais um traço bastante característico do falar dos marvanenses, ainda que só dos mais idosos:

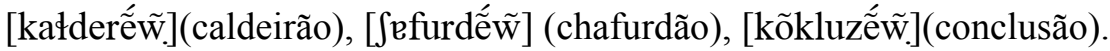

Em posição átona medial, verifica-se frequentemente uma redução no ditongo $[\tilde{\mathfrak{e}} \tilde{\mathrm{w}}]^{17} \mathrm{e}$, em, posição postónica, esta é acrescida de uma desnasalação, passando a $[\mathrm{e}]$ ou $[\mathrm{u}]$ :

(castanhãozão);
[furẽzínu] (furãozinho),

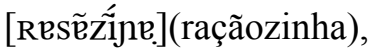
$\left[\mathrm{ke} \int \operatorname{tej} \tilde{\mathrm{e} z} \tilde{\mathrm{e}} \tilde{\mathrm{w}}\right]$

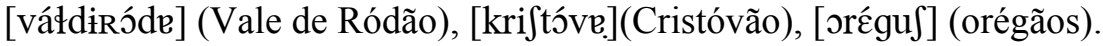

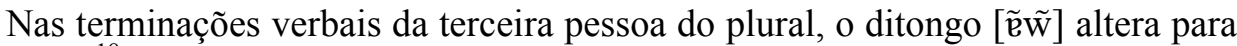

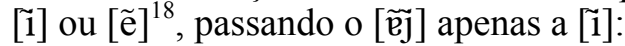

[f́́̃ẽ] (fecham), [kúdẽ](cuidam), ['́rĩ] (eram), [fórĩ](foram);

[ebrîrî](abrirem), [diz̃i] (dizem), [kómî] (comem).

\subsection{Consonantismo}

No consonantismo não se verifica uma variação tão acentuada como no vocalismo. Contudo, são de salientar algumas mutações, entre as quais entre [b] e $[\mathrm{v}]^{19}$. Embora este seja um traço característico dos falares setentrionais, surgem muitos vocábulos a ilustrá-lo:

\footnotetext{
${ }^{14}$ Cf. BAPTISTA, 1967: 45.

${ }^{15}$ Cf. BAPTISTA, 1967: 46. Além da desnasalação, Cândida Baptista registou frequentemente uma queda da vogal final.

${ }^{16}$ Cf. BAPTISTA, 1967: 60. A autora considera que "dentro do condicionamento em que se verifica a palatalização de a tónico oral e nasal (...), encontra-se, também, a palatalização do primeiro elemento

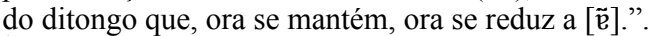

${ }^{17}$ Cf. VASCONCELOS, 1987: 94. Além deste contexto, segundo este autor, a redução também se verifica em próclise.

${ }^{18}$ Cf. BAPTISTA, 1967: 60, 61.

${ }^{19}$ Cf. VASCONCELOS, 1987: 95. Na sua perspetiva, as trocas entre [b] e [v]. não caracterizam a maior parte dos dialetos do Sul, à exceção de Barrancos e de Vila Real. O autor justifica a troca nestas localidades por influência do espanhol falado nas localidades vizinhas, pois nesta língua não existe atualmente o [v].

Sendo Marvão também um concelho de raia, a abundância de vocábulos em que se verifica a troca dẹ[v.]por[b].poder-se-á explicar desta forma, contudo, muitas são também as palavras que ilustram o fenómeno inverso, ou seja, a troca de [b] por [v], como ilustram os ejemplos acima apresentados.

BOLÉO, 1951: 28. Este autor considera a troca entre [v] e [b] muito fácil de ocorrer, especialmente entre a labiodental e a bilabial fricativa: "basta uma aproximação dos lábios para se passar da primeira à segunda ou, inversamente, um ligeiro relaxamento muscular para que a bilabial se transforme em
} 
[besíne] (vacina), [berếde] (varanda), [berizére] (varejeira);

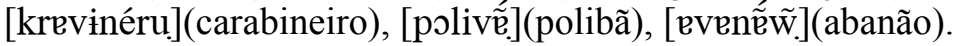

De destacar também a palatalização de $[1]^{20}$ e $[n]$, quando seguidas da semivogal palatal $[\mathrm{j}]$, passando a $[K]$ e $[\mathrm{n}]$ respetivamente:

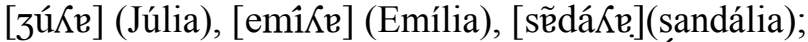

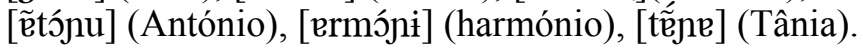

\section{Principais aspetos morfossintáticos do falar de Marvão}

O Falar de Marvão apresenta características morfossintáticas que o distinguem claramente da língua padrão; todavia, algumas derivam de fenómenos fonéticofonológicos.

$\mathrm{Na}$ classe do nome, é de destacar a formação do plural nos vocábulos terminados em lateral alveolar. Contrariamente à norma, apresentam uma terminação regular, com manutenção do -1 - intervocálico ${ }^{21}$, a qual poderá deverse à proximidade com Espanha e à formação dos plurais no castelhano:
[evẽtálif.](aventais),
[pepélif].](papéis),
[berílis]
(barris), [3iresólifj].(girassóis), [Reúlifj].(Rauis).

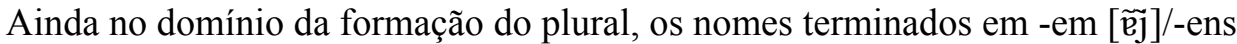

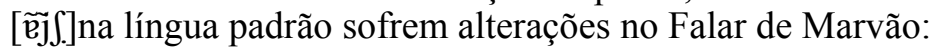

- formam o plural em -as:

[fuRázê] (forragens), [garáze $\left.\int\right]$ (garagens), [márze $\left.\int\right]$ (margens), [órdef].](ordens);

- formam o plural em -es:

[ómif]](homens), [rigwázif] (linguagens), [baRá3iff](barragens).

\footnotetext{
labiodental.” Assim se explica que em português apareçam palavras em que o [b] é proveniente de um [v] e que existam vocábulos com duas variantes de grafia e pronúncia, como sucede com "taberna e taverna, cobarde e covarde".

BAPTISTA, 1967: 65. OSSENKOP, 2006: 670. De acordo com a última autora citada, ao contrário do que sucedeu em Herrera, em que se verificou um "betacismo", ou seja, um predomínio do $b$ em relação ao $v$, nas povoações fronteiriças de Valência de Alcântara, mantém-se a oposição fonológica entre $/ \mathrm{b} / \mathrm{e} / \mathrm{v} /$. Este panorama linguístico justifica a pouca influência desse traço da língua espanhola nas localidades de raia, como é o caso de Porto da Espada, Fronteira, Galegos, Pitaranha, Santo António das Areias e Beirã.

${ }^{20}$ Cf. VASCONCELOS, 1987: 94. O autor considera este fenómeno a continuação moderna do fenómeno de palatalização de [1] em [ $\lambda]$ por influência de uma semivogal palatal, dando origem a palavras do tipo "filha", do lat. FILIA. BAPTISTA, 1967: 72.

${ }^{21}$ Cf. BATISTA, 1967: 92; VASCONCELOS, 1987: 104. O linguista apresenta esta formação do plural como sendo característica do Norte de Portugal, mais propriamente de Trás-os-Montes.
} 
Como já foi referido anteriormente, existe neste falar uma grande tendência para a monotongação. Esta redução influencia também a formação do plural dos nomes

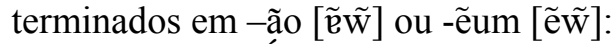
[bałkố].]balcões;

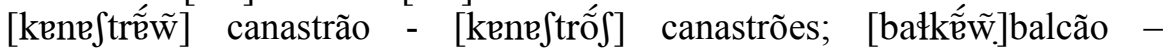
[kõkluzốf.]conclusões.

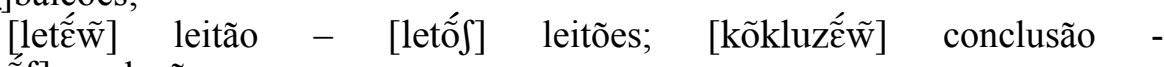

No que diz respeito ao género, alguns nomes apresentam mudança relativamente à norma, a qual corresponde à alteração da vogal final, sendo mais frequente a passagem dos femininos a masculinos do que o inverso:

[bíberu](víbora), [ałkû́nu] (alcunha), [esukereru] (açucareira);

[Spináfres].(espinafres), [midrunére] (medronheiro), [Ríze $]^{22}$ (riso).

No entanto, são ainda frequentes os apelidos masculinos alterados para o feminino:

[migéle](Miguel), [viléze](Velez), [emedóre] (Amador).

$\mathrm{Na}$ classe dos adjetivos, é de salientar a construção do superlativo absoluto sintético. Para além de formas do tipo "velhaquíssemo", "regíssemo", a noção de superlativo muitas vezes é dada através de aumentativos e diminutivos:

"Ela é cá uma alcovetêrona!"

"Tudo está limpinho, até encadeia!"

A superlativação é ainda conseguida através de expressões metafóricas e comparações:

"Levar porrada de três em pipa." (levar muita porrada);

"Nã gramar nem com molho de tomate." (odiar, não gostar mesmo nada);

"Ser com'a mantega em focinho de cão." (ser muito rápido, célere);

"Ser más arreganhado q'um cão de caça." (expressão que se utiliza quando alguém é muito friorento).

No que diz respeito aos pronomes pessoais, verificam-se bastantes diferenças relativamente à norma. Citamos aqui apenas algumas. Assim, quanto à primeira pessoa, é de referir que, quando o pronome integra o segundo membro de uma comparação, assume a forma "mim":

"Ele é más novo ca mim."

Na primeira pessoa do plural, o pronome oblíquo átono "nos" é substituído por "mos"23, provavelmente por analogia com o "me" da primeira pessoa do singular: "O professor nã mos batia".";

\footnotetext{
${ }^{22}$ Esta alteração poder-se-á explicar devido à influência espanhola.

${ }^{23}$ Cf. BATISTA, 1967: 98; VASCONCELOS, 1987: 107.
} 
"Os guardas apanharem-mos ali de surpresa.".

Quanto à terceira pessoa, o pronome "lhe", "lhes" é usado como "le", "les"24, sucedendo o mesmo com as formas contraídas com artigos:

"Agora já nã l'ensino nada.";

"Era só assobier-le.";

"Mando-la entregar hoje.";

"Ê paguê-las logo todas.".

Em situações em que o pronome oblíquo da terceira pessoa desempenha a função de complemento direto e vem antes do verbo, apresenta as formas -no, -na, -nos, -nas (e não -o, -a, -os, -as, como no português padrão), devido a uma influência da consoante nasal que o antecede:

"Nã há quem no compre.";

"Bem no sei eu!".

Em posição enclítica, a sua forma depende da terminação do verbo, havendo neste contexto muitas diferenças relativamente à norma, de que se apresentam aqui apenas alguns exemplos:

[efízjuír] (Ế fízi-o ir.);

[fốmizjuvérốti] (Fômezi-o ver onte.);

[pốzjetốtekốesebrikikedére] (Põsi-a tonta com essa brincadera.).

No que respeita à posição do pronome complemento, contrariamente à língua padrão, este surge antes do sujeito:

"Já nã sê o que m’ela disse.".

Por vezes, assiste-se a uma repetição do pronome complemento indireto, dando origem a formas pleonásticas:

"Quem te disse a ti qu'isso era verdade?";

"Dês ma mim livre!";

"Quem nos manda a nós andar nisto!".

Na subclasse dos pronomes demonstrativos, embora já só nas comunidades mais idosas e das aldeias mais isoladas, verifica-se o uso das formas "aquesse", "aquessa", "aquesses", "aquessas", em vez das normalizadas "esse", "essa", "esses", "essas":

"Aquesse carro nã m'é estranho.";

"Aquessa herdade é da mnha famila.".

\footnotetext{
${ }^{24}$ Cf. BATISTA, 1967: 98; VASCONCELOS, 1987: 107. Este autor alerta para a analogia entre a forma dativa do pronome -"le"- e a sua semelhança com a forma do espanhol. Considera ainda que o uso de uma forma igual no singular e no plural se deve a um fenómeno de analogia com a forma "se".
} 
O mesmo se passa com as formas "aqueste", "aquesta", "aquestes", "aquestas", em vez de "este", "esta", "estes", "estas":

"Naquesta casa é qu'mê criê.";

"Naqueste bairro tudo se conhece.".

De salientar, ainda na subclasse dos pronomes, uma alteração que se verifica no interrogativo: em substituição do invariável "que", usa-se a forma "qui":

"Qui quer ela?"

"Qui l'hamos de fazer?"

No que respeita às formas de tratamento, entre pessoas íntimas ou da mesma idade, usa-se o pronome "tu". Quando alguém mais novo aborda um interlocutor mais velho ou alguém se dirige a uma pessoa desconhecida ou em relação a quem presta reverência, fá-lo usando as formas "você", "vomecê", "omecê", "vossemecei" ou"vossemecê",25, usando-as frequentemente depois de um vocativo:

"Ó menina, vomecê nã quer cá jantar?".

Dependendo do grau de à-vontade que se tem com o interlocutor, assim se usam as expressões "ti", "senhô" ou "dona":

"Ó ti Maria, abra-me lá o portão!";

"Ó senhô Julho, deia-me lá o copo.";

"Ó dona Clara, por favor, nã s'incomode.".

Estas três formas são usadas também na terceira pessoa. No contexto familiar, entre marido e mulher, usam-se as seguintes formas de tratamento:

"o mê", "a minha";

"o patrão", "a patroa";

"a mnha Maria" (mesmo que a esposa tenho outro nome qualquer);

"o mê senhor"26.

No vasto paradigma dos verbos, verificam-se imensas alterações relativamente à norma, muitas delas motivadas por fenómenos fonéticos, como sucede com a alteração das vogais temáticas:

"Aquelas roseras piquem munto.";

"Antigamente samiévem munto más.";

"Andávimos a trabalhar de sol a sol.";

"Ele veve sozinho há uma data d'anos.".

No Presente do Conjuntivo, para além de uma alteração da vogal temática, verifica-se um recuo na acentuação ${ }^{27}$, passando a forma verbal de grave a

\footnotetext{
${ }^{25}$ A forma de tratamento "Vossa Mercê", segundo CINTRA, 1986: 26, nos fins do século XIV, era tratamento real, mas nos finais do séc. XV era tratamento corrente para fidalgos e mesmo "para gente não tão altamente qualificada". Esta tem evoluído ao longo dos séculos, sendo atualmente "você" a fórmula mais diminuta.

${ }^{26}$ Esta surge de forma mais esporádica.
} 
esdrúxula. Mesmo os falantes mais jovens e cultos, que não alteram o timbre da vogal, recuam a acentuação neste tempo verbal:

"Supônhamos que chegas atrasado, como é qu'abrimos a porta?";

"Mesmo que le díguimos isso, ela nã acredita.".

No que diz respeito ao Gerúndio, é de salientar a sua flexão, sendo conjugado em todas as pessoas:

"Im andando mal, já nã vo à rua todos os dias.";

"Em acabandes esse trabalho, podes sair.".

Relativamente à segunda pessoa do plural, nunca é usada pelos falantes e mesmo os mais jovens e escolarizados a substituem pela terceira do plural ${ }^{28}$ :

"Vocês devem chegar lá cedo.";

"Vocês andim depressa, por isso nã vos apanho."

No entanto, alguns idosos conjugam os verbos na segunda pessoa do plural, usando formas verbais arcaicas:

"Vocês ganhêdes poco, mas ainda fazêdes menos.";

"Vocês sêdes capazes de ir."

\section{Léxico}

O domínio, por parte dos falantes, do léxico recolhido varia muito em função das suas características. Muitos vocábulos, especialmente relacionados com as atividades agrícolas, são conservados somente pelos mais idosos, não sendo reconhecidos pelas camadas mais jovens. O conhecimento do domínio do falar, nas suas várias dimensões, pelas diversas classes etárias abaixo da que definimos na primeira fase deste estudo permitir-nos-á saber mais concretamente de que forma o Falar de Marvão continua a passar de geração em geração, apesar dos muitos fatores que no dia-a-dia contribuem para que as suas especificidades se vão perdendo.

Até ao momento, ainda não foi feito um estudo mais exaustivo do vasto léxico recolhido, pelo que apresentamos aqui apenas uma pequena amostra do vocabulário marvanense, distribuída por alguns temas. De notar, contudo, que o vocabulário aqui incluído não exclui o uso, no concelho, de outras palavras com diferentes formas, mas com o mesmo significado.

\subsection{Vocabulário}

a)Terra

\footnotetext{
${ }^{27}$ Cf. BATISTA, 1967: 105; VASCONCELOS, 1987: 113.BATISTA, 1967: 106; VASCONCELOS, 1987: 112.

${ }^{28}$ Cf. BATISTA, 1967: 105; VASCONCELOS, 1987: 113.
} 
agulhero [eguKéru] - s. m. Buraco feito numa parede ou num muro, com vista a servir de passagem.

cartachal [kertefái] - s. m. Pequena parcela de terreno. Prédio pequeno.

chabarco [Sebárku] - s. $m$. Tanque escavado no chão.

linchera [Tifére]- $s . f$. Terreno ocupado por canchos e giestas, de tamanho maior que a "marrada".

marrada [meráde] - s. f. Terra onde não chega o arado, logo não cultivada, povoada por ervas bravas e pedras.

b)Animais

assario, a [eseriu, e] - adj. De raça grande.

avental [evẽtál] - $s . m$. Bocado de pano ou de cabedal que se ata à barriga dos carneiros e dos bodes para os impedir de cobrir as fêmeas.

barrelero, a [beriléru, $\mathrm{e}$ ] - adj. Diz-se do animal que fica com a barriga grande por comer mal.

bonico [bunîku] - s. m. Excremento de animal.

gachela [ga $\int_{\varepsilon}^{\prime}$ le] - adj. Touro que tem os cornos virados para baixo.

c)Plantas

calcinha [katríne]- $s . f$. Anel que permite distinguir os cogumelos comestíveis dos venenosos.

lentresquero [lẽtrifkéru] - $s . m$. Oliveira brava que nunca dá fruto.

piorno [piórnu] - $s$. $m$. Planta silvestre parecida à giesta, que dá flores amarelas e bagas, cujo nome científico é retama monosperma.

unha-gata [ǘnegáte] - $s . f$. Vagem nova, acabada de se formar.

verguenta [virgếte] - s. $f$. Saco de sementes produzido pelo piorno.

d)Fainas, técnicas e alfaias agrícolas

afaiancar [efeiẽkár] - v. Cortar de forma grosseira, sem ser pela raiz.

arrelvar [eRełvár] - v. Dar a primeira lavra à terra.

fuero [fuéru] - s. $m$. Pau comprido, que se aplicava às carretas e às carroças, com

vista a aí espetarem os molhos dos cereais, ampliando assim a carga.

garrancho [geR $\left.\tilde{\mathfrak{P}} \int \mathrm{u}\right]$ - $s$. $m$. Pau utilizado para agarrar o gado ovino e caprino.

guarda-ladrão [gwárdeledré̃ $\tilde{w}]-s . m$. Local para onde cai a maquia de azeite que

fica para o dono do lagar.

e)Habitação/Lar

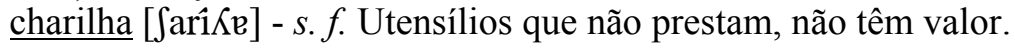

infusa [ifúze] - 1. s. f. Cafeteira. 2. s. $f$. Recipiente para líquidos, com uma asa lateral, feita de barro ou de metal.

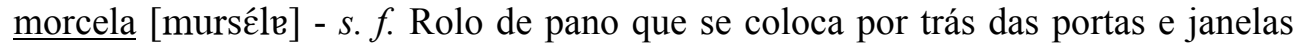
para calafetar.

orelo [orélu] - $s . m$. Tipo de rodilha usada para levar os cântaros à cabeça.

terrea [tikée] - adj. Designação atribuída à casa com um só piso. 
f)Homem - Alimentação

cloque [klóki] - s. m. Beberete, lanche.

envacada [ẽvekáde] - adj. Diz-se da melancia quando apresenta uma cor rosa e não tem doce.

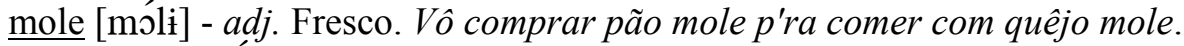

motreco [motréku],- s. m. Pedaço de pão, geralmente duro.

xaramango $\left[\int\right.$ eremếgu $]-s . m$. Pão com enchidos e toucinho. O.m.q. zangalhana.

g)Homem - Ações

atafina [etefíne] - s.f. Azáfama.

atêgar [etegár] - v. Aguentar.

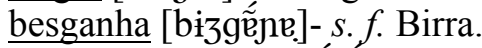

correr ó patalô [kuRéropetteló] - perif. gram. Correr de forma desengonçada.

desalvorir [dizałvurir] - v. Fugir; evadir-se.

h)Homem - Doenças

alacado, a [elekádu, e ] - adj. Com pouca saúde, débil.

belancoso, a [bilẽkózu,.óze] - adj. Adoentado.

cabras [kábres] - s.f. pl. Manchas que surgem nas pernas das mulheres, provocadas

pelo excesso de calor.

cobradura - [kubredúre] - s. $f$. Hérnia.

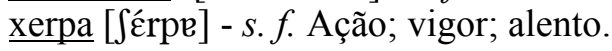

i)Homem - Vestuário

afogadora [efugedóre] - s. f. Gargantilha.

afunda [efú́de] - s. $f$. Espécie de cinta usada para proteger as quebraduras.

às três quinze [ástréfkízì] - adj. Diz-se da roupa com pouca apresentação e que causa espanto a quem a vê vestida.

efunequer [ifunikér.] - v. amarrotar.

ropa-de-trazer [rópeditrezér] - s. $f$. Roupa de usar no trabalho ou por casa.

j)Homem - Características Físicas

aimano, a [ajménnu, e] - adj. Airoso, bem parecido.

cartucho, a [kertúfu, e] - adj. Diz-se da pessoa que é baixa e gordinha.

elaboçado, a [elebosadu, e] - adj. Gordo.

entranquelhado, a [ẽtrẽki Kádu, e.]- adj. Diz-se daquele que junta os joelhos quando

anda; canejo.

marrada [meráde] - s.f. Zona da cara em que a barba ficou mal cortada.

k)Homem - Características Psicológicas

albolaia [ałbuláje] - adj. Diz-se daquele que anda com a cabeça no ar, que não tem

muito juízo.

corrécio, a [kuRésju, e] - adj. Que se dá bem com toda a gente; popular. 
encrenca [ẽkrếkr] - adj. Pessoa que gosta de ditar sentenças, mesmo que não perceba muito do assunto.

estraga-albardas [iftrágałbárdef] - adj. Gastador; pessoa sem auto-gestão.

faguntero, a [fegũtéru, e] - adj. Reinadio; simpático.

1)Homem - Profissões

balfurnhero [batfurnéru] - $s$. $m$. Tendeiro; vendedor ambulante.

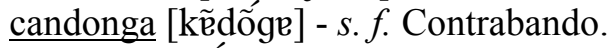

emboque [ẽbóki] - s. m. Emprego; local onde se instalar.

gente dos almofarizes [zẽtiduzałmuferizif $]$ - $s$. $f$. Gente da terra; gente do campo. lavrega [levrége] - s. m. Lavrador.

\subsection{Alcunhas}

No decorrer da recolha, muitas foram as alcunhas que nos surgiram; aliás, estas constituem uma marca do Alentejo e Marvão não é exceção. Na verdade, poucas são as pessoas que não são conhecidas por um anexim e algumas chegam mesmo a ser brindadas com mais do que um. Sendo assim, optámos por incluir nesta parte alguns exemplos dessa riqueza onomástica.

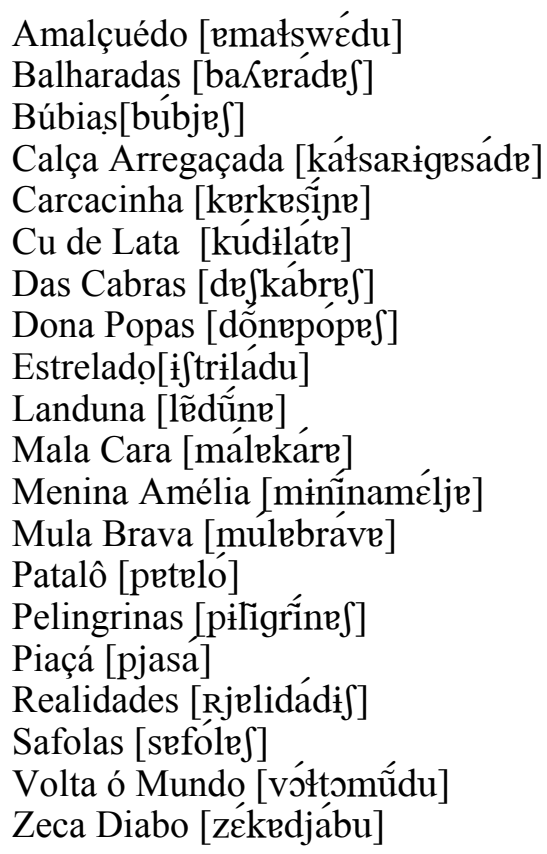




\subsection{Provérbios e máximas populares}

Finalmente, é também muito grande a riqueza de provérbios e máximas populares. Estes foram surgindo naturalmente aquando da aplicação dos inquéritos e, principalmente, nas muitas conversas informais que se vão travando no dia a dia. Deles, damos aqui apenas alguns exemplos:

“a boa sardinha entra p'lo portal da vinha." [ebóeserdíneếtreplupurtáłdevíne] A boa sardinha aparece quando as uvas começam a amadurecer.

"as premeras sã vassoras, as segundas sã senhoras."

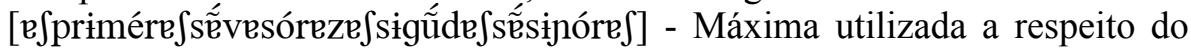
casamento.

"avezo-se a velha ós bredos, agora lambe-l' os dedos." [evizósevéর̧eszbréduzegórelé́biluzdéduf] - O que custou foi começar, agora não se para.

“duas horas em Marvão, nôte na mão." [dúezórezếmervếw̃nótinemếw]] Devido à sua orografia, no Inverno, às duas da tarde, põe-se o sol em Marvão.

"já entrô agosto; quem malhô, malhô, quem nã malhô assim se fecô."

[3áẽtrórgoftukếmeKómeKókếnếmeKóesísifikó] - Quem deixa passar o tempo de fazer as coisas, depois já não tem hipótese de as executar.

"lume grande e água quente fazem a mulher intlegente." [lû́migrếdiiágwekếtifázẽemuḰ́rîtlizếti] - $\quad$ Melhores condições proporcionam à mulher uma melhor ação.

"o bom soa, o mal avoa." [ubốsóeumálevóe] - O bem sabe-se depressa, mas o mal sabe-se ainda mais rapidamente.

"onde o burro cai é que leva as varadas.” [ốdiubúrukájékilévázverádes] - Há que aplicar o castigo na hora certa.

"quanto mas ruim, é a lenha, mas fumo deta." [kwếtumázRuî́celếnemáffứmudéte] - Quanto pior é a pessoa, pior são os seus atos.

"tudo nos chega se a vida nos atura." [túdunufégesevídenuzetúre] - À medida que vamos envelhecendo, vão as doenças aparecendo.

\section{Conclusão}

Iniciado o estudo sobre o Falar de Marvão, muito há ainda por explorar nesta temática. A investigação em curso, no âmbito do doutoramento em Linguística na Universidade de Évora, permitirá continuar a conhecer mais aprofundadamente as particularidades deste falar, bem como explorar outras variantes.

Numa primeira etapa, o estudo visou sobretudo dar conta da variação diatópica ou dialetal existente no concelho de Marvão, evoluindo posteriormente para uma perspetiva sociolinguística. Analisadas as principais características do falar usadas pelos mais velhos e iletrados, torna-se importante conhecer até que ponto os mais 
jovens e instruídos continuam, ou não, a dar-lhe continuidade e que diferenças existem. Para além disso, constatadas diferenças entre algumas aldeias do concelho em estudo, há que perceber as suas motivações e a evolução das assimetrias. Sendo Marvão um concelho de raia, até onde se estende o seu falar? Sabe-se que a fronteira política, mais uma vez, não corresponde à linguística e que nas localidades espanholas fronteiriças se fala português. Contudo, quem o preserva ainda? Como se mantém esse conhecimento nas várias classes etárias? Que diferenças existem relativamente a outras localidades marvanenses? Que influências recebeu este falar do castelhano e de outras línguas?

Eis um conjunto de questões às quais a investigação em curso visa dar resposta.

\section{Referências bibliográficas}

BAPTISTA, Cândida da Saudade C. (1967): O Falar da Escusa. Dissertação de licenciatura policopiada, apresentada à Universidade de Lisboa.

BOLÉO, Manuel de Paiva (1942): O Estudo dos Dialectos e Falares Portugueses. Coimbra: Universidade de Coimbra.

- (1951): "Dialectologia e História da Língua. Isoglossas Portuguesas", Boletim de Filologia, XII, Lisboa: Centro de Estudos Filológicos, pp. 1 - 44.

- (1974): Estudos de Linguística Portuguesa e Românica vol. I Dialectologia e História da Língua. Coimbra: Universidade de Coimbra.

BOLÉO, Manuel de Paiva e SILVA, Maria Helena Santos (1962): "O Mapa dos Dialectos e Falares de Portugal Continental". Boletim de Filologia XX, fasc. $1 \mathrm{e}$ 2. Lisboa: Centro de Estudos Filológicos, pp. 85 - 112.

CARVALHO, José G. Herculano de (1962): "Notas sobre o Vocalismo Antigo Português: Valor dos Grafemas $e$ e $o$ em Sílaba Átona”. Revista Portuguesa de Filologia, XII, Coimbra: Universidade de Coimbra, pp. 17 - 39.

CASTRO, Ivo (2004): Introdução à História do Português (2. ${ }^{a}$ ed.). Lisboa: Edições Colibri (2006).

Censos 2001 - Resultados Definitivos do Alentejo (2001): Lisboa: Instituto Nacional de Estatística.

Censos 2011 - Resultados Provisórios (2011): Lisboa: Instituto Nacional de Estatística.

CINTRA, Luís F. Lindley (1971): "Nova Proposta de Classificação dos Dialectos Galego-Portugueses", Boletim de Filologia XXII. Lisboa: Centro de Estudos Filológicos, pp. 81-116.

- (1983): Estudos de Dialectologia Portuguesa. (2. ${ }^{a}$ ed.) Lisboa: Sá da Costa Editora (1995).

- (1972): Formas de tratamento na Língua Portuguesa. (2a ed.) Lisboa: Livros Horizonte (1986).

COELHO, Possidónio M. Laranjo (2001): Terras de Odiana- Subsidios para a sua história documentada. Medobriga- Aramenha-Marvão Ibn Maruan- Revista 
Cultural do Concelho de Marvão, no 11 (ed. especial). Lisboa: Câmara Municipal de Marvão, Edições Colibri. (fac-simile da edição de 1924)

CUNHA, Celso e CINTRA, Lindley (1985): Breve Gramática do Português Contemporâneo (18 a ed.). Lisboa: Edições João Sá da Costa (2006).

- (1987): Nova Gramática do Português Contemporâneo (4 ${ }^{\mathrm{a}}$ ed.). Lisboa: Edições João Sá da Costa (1984).

HUBER, Joseph (2006): Gramática do Português Antigo. (2 ${ }^{\mathrm{a}}$ ed.) Lisboa: Fundação Calouste Gulbenkian (1933). Trad. Maria Manuela Delille.

Ibn Maruan - Revista Cultural do Concelho de Marvão, n ${ }^{\circ} 14$ (Número especial), Nova Carta Arqueológica do Concelho de Marvão (2007). Lisboa: Edições Colibri, Câmara Municipal de Marvão.

LÜDTKE, Helmut (1953): "Fonemática Portuguesa- II Vocalismo". Boletim de Filologia XIV, Lisboa: Centro de Estudos Filológicos, pp. 197 - 217.

- (1956): Die Strukturelle Entwicklung des romanischen Vokalismus. Bonn: Romanisches Seminar an der Universität Bonn.

- (1957): "Beiträge zur Lautlehre portugiesischer Mundarten." CATALÁN, Diego (ed.) Miscelânea homenaje a André Martinet: estruturalismo e historia. La Laguna: Universidad de la Laguna, vol. 1, pp. 106-112.

Marvão- Obra Única do Homem e da Natureza (1999). Marvão: Câmara Municipal de Marvão. Documento de Pré-Candidatura de Marvão a Património Mundial.

MATEUS, Maria Helena Mira et alii (1983): Gramática da Língua Portuguesa (5. a ed.). Lisboa: Editorial Caminho (2003).

NETO, Serafim da Silva (1952): História da Língua Portuguesa (6. ed.). Lisboa: Dinalivro (1992).

NUNES, José Joaquim (1919): Compêndio de Gramática Histórica Portuguesa. Fonética e Morfologia ( $8^{\mathrm{a}}$ ed.) Lisboa: Livraria Clássica Editora (1975).

OSSENKOP, Chistina (2006): "La situación lingüística actual de las variedades portuguesas en la franja fronteriza de Valencia de Alcántara" Estudios Extremeños - Revista Histórica, Literaria y Artística - Tomo LXII, n ${ }^{\circ}$ II MayoAgosto. Badajoz: Departamento de Publicaciones Exelentísima Diputación Provincial, pp. $661-681$.

SIMÃO, Teresa (2011): O Falar de Marvão: pronúncia, vocabulário, alcunhas, ditados e provérbios populares. Lisboa: Editora Colibri.

TEYSSIER, Paul (1980): História da Língua Portuguesa (8. a ed.) Lisboa: Livraria Sá da Costa Editora. (2001). Trad. Celso Cunha.

VASCONCELOS, J. Leite de (1897): Mapa dialectológico do Continente Português. Lisboa: Guillard, Aillaud \& Cia.

— (1890- 1892): "Dialectos Alentejanos" in Revista Lusitana II, Porto: Livraria Portuense, pp. $15-45$.

- (1896): "Dialectos Alentejanos" in Revista Lusitana IV, Lisboa, pp. 13 - 77; $215-246$.

- (1897): Mapa dialectológico do Continente Português. Lisboa: Guillard, Aillaud \& Cia. 
- (1901): Esquisse d'une Dialectologie Portugaise (3.aed.) Lisboa: Instituto Nacional de Investigação Científica - Centro de Linguística da Universidade de Lisboa (1987).

- (1929): Opúsculos - vol. IV Filologia. Coimbra: Imprensa da Universidade. 